\title{
PSYCHOLOGICAL PROFILE OF PATIENTS WITH CHRONIC LOW BACK PAIN
}

Shaista $\mathrm{Ali}^{1}$, Zahin Anjum ${ }^{2}$, Samir Khan $\mathrm{Kabir}^{3}$, Muhammad Waqar ${ }^{4}$, Abdul Satar $^{5}$, Muhammad Arif $^{6}$

\section{ABSTRACT:}

\section{OBJECTIVES:}

To assess the frequency of depression, anxiety, and stress in patients with Chronic Low Back Pain (CLBP) using Depression Anxiety Stress Scale (DASS-42).

\section{METHODOLOGY:}

This descriptive study was performed from January 2019 to June 2019. All those patients with chronic low back pain with duration of more than 6 months were included. Patients below 20 and above 60 years were excluded to eliminate the effect of extreme ages. The Depression Anxiety Stress Scale (DASS-42) was used in this study.

\section{RESULTS:}

In this study, a total of 127 patients were successfully interviewed. The mean age of the sample was 36.46 (SD \pm 7.38 ) with a minimum age of 22 years and maximum of 59 years. Out of these 127 patients, $83(65.4 \%)$ were female while $44(34.6 \%)$ were male patients. The minimum duration of chronic low back pain in our patients was 8 months while the maximum was 55 months with a mean of 28 months (SD 9.9). The mean DASS score for depression was 11.8 (SD \pm 4.23 ), anxiety was 7.5 $(S D \pm 2.9)$, stress was 12.1 (SD \pm 4.0$)$. Similarly, both genders had equal level of depression and anxiety but females were more experiencing the stress.

\section{CONCLUSION:}

Abnormal levels of stress anxiety and depression are a common finding in our population with CLBP.

KEYWORDS: Chronic Low Back Pain, Psychosocial Disorders, Depression, Anxiety, Stress

How to cite this article:

Ali S, Anjum Z, Kabir SK, Waqar M, Satar A, Arif M. Psychological Profile of Patients with Chronic Low Back Pain. J Gandhara Med Dent Sci. 2021;8(2): 3-8

\footnotetext{
Correspondence

${ }^{5}$ Abdul Satar, Department of Orthopedics and Spine surgery. Hayatabad Medical Complex,Peshawar Cell\# +92-333-9322022

Email:a_khan37@yahoo.co.uk

${ }^{1}$ Department of Human Development \& Family Studies, College of Home Economics, Peshawar

${ }^{2}$ Department of Food \& Nutrition Sciences, College of Home Economics, Peshawar

${ }^{3}$ Department of Orthopedics, Naseer Teaching Hospital, Peshawar

${ }^{4}$ Department of Orthopedics and Spine surgery . Hayatabad Medical Complex, Peshawar

${ }^{6}$ Department of Orthopedics and Spine surgery . Hayatabad
}

\section{INTRODUCTION:}

Chronic low back pain (CLBP) is the most common musculoskeletal disorder for which patients seek medical help both at primary health care and specialized health care level ${ }^{1}$. CLBP is the most common cause of absence from the work and is defined as back pain persists for more than three months ${ }^{2}$. Back pain may be a symptom of many pathologies, but the most common is of the nonspecific origin or due to disc degeneration ${ }^{3}$. The prevalence of chronic low back pain is on the rising both in the developed and developing world. In Europe and North America, the prevalence is from 5 to $10 \%^{2,4}$. Apart from the huge socioeconomic impact the management of chronic low back is 
very difficult and requires multimodal approach $^{5}$. An episode of back pain is common, and every individual suffers from it quite a few times in his life ${ }^{6}$. When and why this acute back pain changes to chronic back pain are not clear yet ${ }^{7}$. It is thought that it is a multifactorial process from genetic predisposition to socioeconomic factors, demographic parameters, obesity, smoking body height, profession, and psychosocial factors. All are studied and found to have some effect on CLBP ${ }^{8-11}$. Psychosocial factors play important role in the chronicity of back pain. Personality types stress, anxiety and depression all are important and should be carefully assessed in managing these patints $^{12}$. It is now very clear that patients with these problems will have unfavourable results of conventional treatment modalities even surgeries ${ }^{13}$. Therefore, it is very important to identify these psychosocial factors as early as possible and address them properly along with conventional therapies to prevent chronicity of back pain and insure better outcome ${ }^{14}$. Psychosocial factors play an important role in the management of these patients but to identify specific factors in a specific patient to address, it is usually difficult and mostly ignored $^{15}$. Being every common aspect of patient management, it is often rarely addressed in clinical practice. This study is an integration of psychological practice into the clinical management of the patients. This will create awareness in this area and will lead to further studies on this topic, as we could not find a local study on this aspect. This study will show the rate of different factors like stress, anxiety, and depression in our local patients.

\section{METHODOLOGY:}

This descriptive study was conducted on patients presented to Department of Orthopaedics \& Spine Surgery Hayatabad Medical Complex, Khyber Girls Medical College, Peshawar, and Aman Hospital Peshawar. The study duration was from January 2019 to June 2019. All those patients with chronic low back pain with duration of more than 6 months were included. Patients below 20 and above 60 years were excluded to eliminate the effect of extreme ages. Patients with spine trauma, infections, and tumours were excluded. Similarly, patients with known psychiatric illness were also excluded. The Depression Anxiety Stress Scale (DASS-42) developed by Lovebird and Lovibond in 1995 was used in this study ${ }^{16}$. It is a comprehensive questionnaire of 42 questions assessing the presence and severity of depression, anxiety, and stress. Each question has 4 possible scores from 0 to 3 . In the end, scores of all three-sub types are rated from normal to extremely severe. All patients fulfilling the above mention criteria and who agree to complete the test were given the Urdu version of DASS-42 or a helper asked them the question, in case of illiterate patients. The demographic data sheet was used to collect demographic information of all the patients. Data analysis was done using SPSS 20.

\section{RESULTS:}

In this study, a total of 127 patients were successfully interviewed. The minimum duration of chronic low back pain in our patients was 8 months while the maximum was 55 months with a mean of 28 months $(\mathrm{SD} \pm 9.9)$.

Table 1: Demographic Details

\begin{tabular}{|c|c|c|}
\hline \multirow{4}{*}{ Gender } & Grouping & $\mathbf{f}(\%)$ \\
\cline { 2 - 3 } & Male & $44(34.6)$ \\
\hline \multirow{4}{*}{ Age } & Memale & $83(65.4)$ \\
\cline { 2 - 3 } & Minimum & 36.4 \\
\cline { 2 - 3 } Status & Maximum & 22 \\
\cline { 2 - 3 } & Married & $113(89)$ \\
\hline \multirow{3}{*}{$\begin{array}{c}\text { Marital } \\
\text { Education }\end{array}$} & Single & $14(11)$ \\
\cline { 2 - 3 } & Higher Secondary & $32(25.3)$ \\
\cline { 2 - 3 } & Primary & $21(16.5)$ \\
\cline { 2 - 3 } & Bachelor & $26(20.5)$ \\
\cline { 2 - 3 } & Higher & $03(2.4)$ \\
\hline
\end{tabular}


Table 2: Descriptive Statistics of DAAS Depression, Anxiety \& Stress.

\begin{tabular}{|c|c|c|c|c|c|}
\hline Scores & $\mathbf{N}$ & Min & Max & Mean & Std.D \\
\hline Depression & 127 & 05 & 23 & 11.85 & 4.2308 \\
\hline Anxiety & 127 & 03 & 19 & 07.57 & 2.9182 \\
\hline Stress & 127 & 05 & 27 & 12.10 & 4.0076 \\
\hline
\end{tabular}

Table 3: Levels of Severity (Depression Anxiety \& Stress) among patients of CLBP

\begin{tabular}{|c|c|c|c|}
\hline \multirow{2}{*}{ Level of severity in CLBP } & \multicolumn{2}{|c|}{ Frequency } \\
\cline { 2 - 4 } & Depression & Anxiety & Stress \\
\hline Normal & 56 & 44 & 20 \\
\hline Minimal & 30 & 23 & 4 \\
\hline Moderate & 37 & 29 & 6 \\
\hline Severe & 4 & 4 & 127 \\
\hline Total & 127 & 100 & \\
\hline
\end{tabular}

Table 4: Gender and DAAS Levels of Severity

\begin{tabular}{|c|c|c|c|c|c|c|}
\hline \multicolumn{7}{|c|}{ Depression } \\
\hline & Normal & Mild & Moderate & Severe & Chi-Square & P-value \\
\hline Male & $28(63.6 \%)$ & $7(15.9 \%)$ & $8(18.2 \%)$ & $1(2.3 \%)$ & \multirow{2}{*}{10.46} & \multirow{2}{*}{0.01} \\
\hline Female & $28(33.7 \%)$ & $23(27.7 \%)$ & $29(34.9 \%)$ & $3(3.6 \%)$ & & \\
\hline \multicolumn{7}{|c|}{ Anxiety } \\
\hline & Normal & Mild & Moderate & Severe & Chi-Square & P-value \\
\hline Male & $24(54.4 \%)$ & $3(6.8 \%)$ & $12(27.3 \%)$ & $5(11.4 \%)$ & \multirow{2}{*}{18.04} & \multirow{2}{*}{0.001} \\
\hline Female & $43(51.8 \%)$ & $23(27.7 \%)$ & $13(15.7 \%)$ & $4(4.8 \%)$ & & \\
\hline \multicolumn{7}{|c|}{ Stress } \\
\hline & Normal & Mild & Moderate & Severe & Chi-Square & P-value \\
\hline Male & $20(45.5 \%)$ & $15(34.1 \%)$ & $8(18.2 \%)$ & $1(2.3 \%)$ & \multirow{2}{*}{28.77} & \multirow{2}{*}{0.001} \\
\hline Female & $61(73.5 \%)$ & $2(2.4 \%)$ & $2(2.4 \%)$ & $18(21.7 \%)$ & & \\
\hline
\end{tabular}

\section{DISCUSSION:}

Psychosocial factors play a vital role in the genesis of CLBP, its management, prognosis, and outcome of conventional treatment ${ }^{17}$. Whether an acute back pain episode will go into the chronic phase much depends on psychosocial factors ${ }^{18}$. Failure to consider these factors at any step leads to failure of treatment. This not only influences the individual but society due to financial burden $^{19}$. In fact, therefore management of CLBP is so difficult. About 30 to $50 \%$ of patients with psychiatric symptoms are missed by their primary care physicians ${ }^{20}$. On-time recognition of these factors like depression and their treatment improves the outcome of CLBP management. This is now well established that treatment of psychiatric disturbances should be an integral part of multimodal management of $\mathrm{CLBP}^{21,22}$. In contrast to other studies, which do not show much difference in male-female patients, in our study there is a striking difference with strong female predominance, ${ }^{23}$ out of 127 patients $83(65.4 \%)$ were female while 44 $(34.6 \%)$ were male. Whether it relates to the work-related problems, insurance and compensation issues in the west need more studies. Most of our patients were with low education level or illiterate and the majority were female patients. Vereckie $E$ et al showed no correlation of CLBP with gender education level and marital status. In our study, we found a predominance of female gender with low education level ${ }^{24}$. Similar to our study using DASS-42 in patients with chronic low back pain Vanshika $S$ reported a mean score for depression 18.83 \pm 5.12 , anxiety $11.06 \pm 2.9$ and stress $17.5 \pm 3.7,{ }^{25}$ compare to their mean scores for sub-types of DASS we have lower scores. The mean 
anxiety score was $7.5(\mathrm{SD} \pm 2.9)$, stress 12.1 $(\mathrm{SD} \pm 4.0)$ and depression $11.8 \quad(\mathrm{SD} \pm 4.23)$. Their sample was small and different setup what may be the cause of the difference. Hong $\mathrm{JH}$ reported depression in $51.5 \%$ of patients with chronic low back pain and anxiety in $42.5 \%{ }^{26}$. Depression and anxiety in their study is as common as in our study. Their sample was small compare to ours and they used different measuring tools like Beck Depression Inventory (BDI) and Beck Anxiety Inventory (BAI). Rush AJ reported depression in $59 \%$ of patients while Sagheer MA et al reported $48.7 \%$ depression and anxiety in $55 \%{ }^{27,}{ }^{28}$. The anxiety level they reported in Pakistan is also very high but the scoring tool was different and they reported that $38.5 \%$ of patients had borderline anxiety.

Stress, which is the third factor in DASS is the least studied one. Studies on frequency of stress disorder in patients with CLBP using this scale are very few. Most studies focused on the frequency of depression and anxiety in these patients using the DASS-42 scale. Depression and anxiety are considered the most important psychological factors in CLBP. The three major aspects of the chronic low back are usually defined as somatic, depressive and social $^{29}$. It may be understandable that with chronic conditions with time the stress anger factor diminishes. The mean DASS stress score in our study was 12.1 ( $S D \pm 4.0)$, Table 2; lower than that reported by Vanshika $S^{25}$. But our study shows that stress is still present in a significant number of patients. Haggman $S$ reported stress abnormalities in 100 patients of CLBP out of $232,{ }^{30}$ out of which $10.3 \%$ were with severe and $6.5 \%$ with extre mely severe stress abnormality. Comparing the depression, stress, and anxiety scores with the level of severity across gender it was showed that both genders had depression and anxiety, but female were more stressed as compared to male.

Psychological factors are as common in our society as any other society. These factors must be considered in managing any patient with chronic low back pain. DASS-42 can satisfactorily find out patients with these abnormalities.

\section{CONCLUSION:}

Psychological factors are the key factor in chronic low back patients and must be addressed with equal caution like any other somatic factor. Any management plan for patients with CLBP without consideration of these psychological factors will be a failure.

\section{LIMITATIONS:}

Other factors effecting psychological health were not address in this study. There are chances that those factors could also be influencing the stress anxiety and depression of chronic low back pain patients.

\section{CONFLICT OF INTEREST: None}

\section{FUNDING SOURCES: None}

\section{REFERENCES:}

1. WHO Scientific Group on the Burden of Musculoskeletal Conditions at the Start of the New Millennium. The burden of musculoskeletal conditions at the start of the new millennium. World Health Organ Tech Rep Ser. 2003; 919:1-218.

2. Parthan A, Evans CJ, Le K. Chronic low back pain: epidemiology, economic burden, and patient-reported outcomes in the USA. Expert Rev Pharmacoecon Outcomes Res. 2006; 6(3):359-69.

3. Bakhsh A. Long-term outcome of lumbar disc surgery: an experience from Pakistan. J Neurosurg Spine. 2010; 12:666-70.

4. Juniper M, Le TK, Mladsi D. The epidemiology, economic burden and pharmacological treatment of chronic low back pain in France, Germany, Italy, Spain and the UK: a literature-based review. Expert Opin Pharmacother. 2009;10(16):2581-92.

5. Gobel H. Epidemiology and costs of chronic pain syndromes exemplifies by specific and unspecific low back pain. Schmerz. 2001;15(2):92-8.

6. Shiri $R$, Karppinen $J$, Leino-Arjas $P$, Solovieva S, Viikari-Juntura E. The association between obesity and low back pain: a meta-analysis. Am J Epidemiol. 2010;171(2):135-54.

7. Williams JS, Ng N, Peltzer K, Yawson A, Biritwum R, Maximova $\mathrm{T}$, et al. Risk factors and disability associated with low back pain in older adults in low and middle-income countries. Results from the 
WHO Study on Global AGEing and Adult Health (SAGE). PLoS ONE. 2015;10(6): e0127880.

8. Louw QA, Morris LD, Grimmer-Somers K. The prevalence of low back pain in Africa: a systematic review. BMC Musculoskelet Disord. 2007;8(105):1-4.

9. Deltonen $M$, Lindross $A K$, Torgerson JS. Musculoskeletal pain in the obese: a comparison with a general population and long-term changes after conventional and surgical obesity treatment. Pain. 2003; 104:549-57.

10. Gilgil E, Kaçar C, Bütün B, Tuncer $T$, Urhan S, Yildirim C, et al. Prevalence of low back pain in a developing urban setting. Spine. 2005;30(9):1093-8.

11. Shiri $R$, Karppinen $J$, Leino-Arjas $P$, Solovieva S, Viikari-Juntura E. The association between obesity and low back pain: a meta-analysis. Am J Epidemiol. 2010;171(2):135-54.

12. Moore JE. Chronic low back pain and psychosocial issues. Phys Med Rehabil Clin. 2010;21(4):801-15.

13. Manek NJ, Macgregor AJ. Epidemiology of back disorders: prevalence, risk factors and prognosis. Curr Opin Rheumatol. 2005;17(2):134-40.

14. Nicholas MK, Linton SJ, Watson PJ, Main CJ. Early identification and management of psychosocial risk factors (-yellow flagsil) in patients with low back pain: a reappraisal. Phys Ther. 2011;91(5):73753.

15. Weiser S, Cedraschi C. Psychosocial issues in the prevention of chronic low back pain-a literature review. Bailliere's Clin Rheumatol. 1992;6(3):657-84.

16. Crawford JR, Henry JD. The Depression Anxiety Stress Scales (DASS): normative data and latent structure in a large nonclinical sample. $\mathrm{Br} \mathrm{J}$ Clin Psychol. 2003;42(2):111-31.

17. Reme SE, Lie SA, Eriksen HR. Are 2 questions enough to screen for depression and anxiety in patients with chronic low back pain? Spine. 2014;39(7): E455-62.

18. Matsudaira K, Konishi H, Miyoshi K, Isomura T, Inuzuka K. Potential risk factors of persistent low back pain developing from mild low back pain in urban Japanese workers. PLoS ONE. 2014;9(4): e93924.
19. Simon GE, VonKorff M. Recognition, management, and outcomes of depression in primary care. Arch Fam Med. 1995;4(2):99-105.

20. Overland S, Glozier N, Krokstad S, Mykletun A. Undertreatment before the award of a disability pension for mental illness: the HUNT study. Psychiatr Serv. 2007;58(11):1479-82.

21. Pignone MP, Gaynes BN, Rushton JL, Burchell CM, Orleans CT, Mulrow CD, et al. Screening for depression in adults: a summary of the evidence for the U.S. Preventive Services Task Force. Ann Intern Med. 2002;136(10):765-76.

22. Kroenke K, Spitzer RL, Williams JB, Lowe B. The Patient Health Questionnaire Somatic, Anxiety, and Depressive Symptom Scales: a systematic review. Gen Hosp Psychiatry. 2010;32(4):345-59.

23. Quint $U$, Hasenburg $H$, Patsalis $T$, Franke GH. Psychosocial stress of inpatients with acute and chronic lumbar syndrome. $Z$ Orthop Unfall. 1998;136(5):444-50.

24. Vereckei E, Susanszky E, Kopp M, Ratko I, Nagy Z, Palkonyai E, et al. Psychosocial, educational and somatic factors in chronic nonspecific low back pain. Rheumatol Int. 2013;33(3):587-92.

25. Vanshika S, Pragyadeep. Impact of short duration (4 weeks) core stability exercises on depression, anxiety and stress status of adult patients with chronic low back pain. J Pharm Biomed Sci. 2012;23(16):14.

26. Hong JH, Kim HD, Shin HH, Huh B. Assessment of depression, anxiety, sleep disturbance, and quality of life in patients with chronic low back pain in Korea. Korean J Anesthesiol. 2014;66(6):444-50.

27. Rush AJ, Polatin P, Gatchel RJ. Depression and chronic low back pain: establishing priorities in treatment. Spine. 2000;25(20):2566-71.

28. Sagheer MA, Khan MF, Sharif S. Association between chronic low back pain, anxiety and depression in patients at a tertiary care center. J Pak Med Assoc. 2013;63(6):688-90.

29. Ellegaard $H$, Pedersen BD. Stress is dominant in patients with depression and chronic low back pain: a qualitative study of psychotherapeutic interventions for 
patients with non-specific low back pain of 3-12 months duration. BMC Musculoskelet Disord. 2012;13:166.
30. Haggman S, Maher CG, Refshauge KM. Screening for symptoms of depression by physical therapists managing low back pain. Phys Ther. 2004;84(12):1157-66.

\section{CONTRIBUTORS}

1. Shaista Ali - Concept \& Design; Data Acquisition; Data Analysis/Interpretation; Drafting Manuscript; Supervision; Final Approval

2. Zahin Anjum - Concept \& Design; Data Acquisition; Data Analysis/Interpretation; Drafting Manuscript; Critical Revision; Supervision

3. Samir Khan Kabir - Data Acquisition; Data Analysis/Interpretation; Drafting Manuscript

4. Muhammad Waqar - Concept \& Design; Critical Revision

5. Abdul Satar - Concept \& Design; Data Acquisition

6. Muhammad Arif - Data Analysis/Interpretation; Critical Revision

LICENSE: JGMDS publishes its articles under a Creative Commons Attribution Non-Commercial Share-Alike license (CC-BY-NC-SA 4.0) COPYRIGHTS: Authors retain the rights without any restrictions to freely download, print, share and disseminate the article for any lawful purpose. It includes scholarly networks such as Research Gate, Google Scholar, LinkedIn, Academia.edu, Twitter, and other academic or professional networking sites. 